\section{Hepatitis B vaccine uptake assessment in India}

\section{Mohan Bairwa \\ Centre for Community Medicine, All India Institute of Medical Sciences, New Delhi, India}

\section{Dear Editor,}

Hepatitis B (Hep B) vaccine was introduced in the Universal Immunization Program (UIP) of 10 States of India in 2007-08. Following Hep $B$ vaccine introduction, Lahariya and colleagues conducted an assessment of Hep B vaccine debut from August to December 2009 to i) ascertain the reasons for reported low coverage; ii) identify operational and programmatic challenges; and iii) derive lessons for further scale up of Hep B and other newer vaccine introductions. Two districts, one nearest and other farthermost to State headquarter were selected from five evaluation States [Punjab (PB), Madhya Pradesh (MP), West Bengal (WB), Karnataka (KA) and Tamil Nadu (TN)].

In the assessment, data were collected through a comprehensive desk review, 143 respondent interviews, a series of cold chain storage observations and immunization site observations of 36 sessions. Lower coverage and higher drop outs were identified of three doses of Hep B vaccine (Hep B3) and three doses of diphtheria, tetanus, and poliomyelitis (DPT) vaccine (DPT3) during the study period. The main reasons behind this were shortage of vaccine, improper or incomplete data recording and reporting, lack of awareness amongst health workers, and not opening of vaccine vials to keep vaccine wastage low.

Birth dose administration has been documented in KA, TN and WB of the 5 states included in the assessment. Other two states ( $\mathrm{PB}$ and $\mathrm{TN}$ ) concerned about vaccine wastage and adverse events following immunization. The incomplete recording and reporting of the birth dose, along with limited knowledge amongst health care providers about age for Hep B birth dose, was an additional ground behind it. No proper reporting formats were in place to record Hep B vaccine; therefore, it is assumed as equal to respective DPT doses coverage by field workers.

Amongst 36 session sites visited, the vaccine stocks and stores were replenished by push mechanism, leading to nil stock position commonly in $56 \%$ state and district levels as well as $60 \%$ primary health centre level stores. Of the ten private sector paediatricians interviewed, three provided Hep B birth dose and five provided coverage reports to the government. There is no provision to supply routine immunization vaccines to private practitioners by government, which was the reason behind non-reporting of vaccine coverage from private sector.

The study documented major lessons were good central and state level oversights, clear policy communications and dissemination of guidelines, quality and timely trainings, effective monitoring and supervision prior and during early stage of introduction, and improvement in recording and reporting.

While small sample size and purposive sampling were the limitations of the study, state selection according to geographic distribution considering wide geographic, cultural and socioeconomic differences, and comprehensive assessment at all levels from field workers to state program managers were the strengths of study.

Of the 25 million infants born every year in India, more than $4 \%$ live with the lifetime risk of developing chronic Hep B infection. About 4\% Indian population were $\mathrm{HBsAg}$ positive and over 100,000 Indians die annually because of Hep B-related illnesses. ${ }^{2}$ Approximately 100 million Hep B carriers live in the member countries of the WHO South-East Asia Region. Despite availability of $95 \%$ effective Hep B vaccine, it was not included in UIP for nearly 2 decades till 2002-03 in selected districts. ${ }^{3}$ Evaluation of newer health interventions plays a crucial role in improving implementation of health programs at field level, however, it is not commonly practiced in India. ${ }^{4}$ Most of the program evaluations are neither properly documented nor published in India. The study at stake is a robust evaluation of new vaccine introduction among five major States. The authors report that findings were not only shared with national program managers for immediate corrective measures in early 2010 but also used for further scale up of Hep B vaccine in all 35 States of India in 2011-12.

Two short reviews done in 2004 and 2007 provide assessments of pilot introduction of Hep B vaccination in India; still, the reports were not widely disseminated. This article summarizes and analyses the findings of two previous assessments with the current one and provides comprehensive recommendations and lessons along with limitations of such assessment. ${ }^{1}$ India has a big private sector for immunization services delivery. However, private sector is assessed in very few program evaluations in India. The private pediatricians were included in the present assessment which is a refreshing approach and suggested consideration of their significant participation in health programs as well as program evaluations. The assessment outlined the findings and programmatic lessons including poor stock management, incomplete recording and reporting, perceived high cost and concern towards wastage of vaccine in multi-dose vial, lesser participation of private sector, and poor
Correspondence: Mohan Bairwa, Centre for Community Medicine, All India Institute of Medical Sciences, New Delhi 110029, India.

Tel: +91.97188.35447.

E-mail: drmohanbairwa@gmail.com

Key words: hepatitis B vaccine, health program, newer health interventions.

Note: the opinions expressed by the author do not necessarily reflect the opinions of the All India Institute of Medical Sciences, New Delhi, India.

Received for publication: 25 December 2013. Revision received: 12 August 2014.

Accepted for publication: 26 September 2014.

This work is licensed under a Creative Commons Attribution 3.0 License (by-nc 3.0).

(C) Copyright M. Bairwa, 2014

Licensee PAGEPress, Italy

Healthcare in Low-resource Settings 2014; 2:2116 doi:10.4081/hls.2014.2116

knowledge of Hep B vaccination schedule amongst healthcare providers. These factors may have been contributed to comparatively low coverage of Hep B vaccine. Later on, the Government of India corrected the majority of issues identified, showing that recommendations based upon robust methodology help in improving program performance. There is a number of vaccine introductions in India since adoption of Hep B vaccine in 10 states of the country. Measles second dose was introduced in 2010; Hep B vaccination scaled up in the entire country in 2011-12, and Haemophilus Influenzae type $b$ (Hib) as pentavalent vaccine was introduced in 2 states in late 2011..$^{5-7}$ Pentavalent vaccine protects from Hep B along with diphtheria, pertussis, tetanus, and Hib. In Kerala and TN, it has been launched in 2011. ${ }^{8}$

Majority of lessons from this evaluation contributed to planning new vaccine introductions in India. The government of India issued welldefined guidelines, changed policy use of opened vials in subsequent immunization sessions, conducted quality trainings prior to the vaccine introduction, and increased supervision and monitoring in vaccine introductions. A post-introduction evaluation of pentavalent vaccine introduction in Tamil Nadu and Kerala states documented major experience and noted that the challenges identified in the Hep $B$ vaccine introduction were not present in pentavalent vaccine introduction. ${ }^{9}$

The pentavalent vaccine has been further scaled up to Gujarat, Haryana, Karnataka, Goa, Jammu, Kashmir and Puducherry in 2012-13 and there is plan for countrywide roll out in $2014 .^{8}$ Similarly, India has developed an indigenous rotavirus vaccine, which is likely to 
be considered for possible introduction in Indian UIP. A number of states in India plan to introduce the vaccine in their state immunization programs. ${ }^{10}$ Thus, such evaluation may help in widely spreading programmatic benefits and improving program performance in India. Vaccine introductions are not that different from the introduction of other health interventions. India aims to achieve Millennium Development Goal 4 and national goals of reducing child mortality and a number of new initiatives are being already implemented and planned for improving child survival in India, under the National Rural Health Mission (NRHM). ${ }^{11}$ The lessons from this evaluation are potential for being used for scale up of other health interventions.

One of the major challenges in health programs in India is the limited focus on evaluations and correctives measures. However, the scenario is apparently changing now and numbers of evaluations are being conducted including common review missions in NRHM. ${ }^{12,13}$ The robust evaluation used for programmatic corrections is likely to benefit program implementation in the country and show health impact.

\section{References}

1. Lahariya C, Subramanya BP, Sosler S. An assessment of hepatitis B vaccine introduction in India: lessons for roll out and scale up of new vaccines in immunization programs. Indian J Public Health 2013;57: 8-14.

2. Verma R, Khanna P, Prinja S, et al. Hepatitis $\mathrm{B}$ vaccine in national immunization schedule: a preventive step in India. Hum Vaccines 2011;7:1387-8.

3 . Government of India. Operational guidelines for Hepatitis B introduction in UIP in India, 2009. New Delhi: Ministry of Health and Family Welfare, Government of India; 2009.

4. Dandona L, Raban MZ, Dandona R. Analysis of evaluations of health system/policy interventions in India. Natl Med J India 2011;24:263-8.

5. Gupta SK, Sosler S, Lahariya C. Introduction of Haemophilus influenzae type b as liquid pentavalent (DPT $+\mathrm{HepB}+\mathrm{Hib}$ ) vaccine in 2 States of India. Indian Pediatr 2012;49:707-9.

6. Verma R, Khanna P, Bairwa M, et al. Introduction of a second dose of measles in national immunization program in India: a major step towards eradication.
Hum Vaccines 2011;7:1109-11.

7. Gupta SK, Sosler S, Haldar P, et al. Introduction strategy of a second dose measles containing vaccine in India. Indian Pediatr 2011;48:379-82.

8. Bairwa M, Pilania M, Rajput M, et al. Pentavalent vaccine: a major breakthrough in India's universal immunization programme. Hum Vaccines 2012;8:1314-6.

9. WHO. Post introduction evaluation of pentavalent (DPT+HepB+Hib) vaccine in Tamil Nadu and Kerala, India, report 2012. New Delhi: World Health Organization Country Office for India Publ.; 2013.

10. Government of India. Press information bureau note on indigenous rotavirus vaccine in India. New Delhi: Government of India Publ.; 2013.

11. Government of India. National rural health mission. Available from: www.nrhm.gov.in

12. Government of India. Sixth common review mission of NRHM. Available from: http://nrhm.gov.in/monitoring/commonreview-mission/6th-common-review-mission-crm.html

13. Lahariya C, Dhawan J, Pandey RM, et al. Inter-district variations in child health status and health services utilization: lessons for health sector priority setting and planning from a cross-sectional survey in rural India. Natl Med J India 2012;25:137-41. 